\title{
Plasma Triglycerides Determine Low Density Lipoprotein Composition, Physical Properties, and Cell-specific Binding in Cultured Cells
}

\author{
Barry J. McKeone, ${ }^{\star}$ Josef R. Patsch, ${ }^{\star}$ and Henry J. Pownall * \\ *Department of Internal Medicine, Baylor College of Medicine, and The Methodist Hospital, Houston, \\ Texas 77030; and ${ }^{\ddagger}$ The Department of Medicine, University of Innsbruck, Innsbruck, Austria
}

\begin{abstract}
The relationship between the plasma triglycerides and the LDL triglycerides of 30 normal and 48 hypertriglyceridemic subjects has been quantified; the data fit a simple adsorption isotherm, LDL triglyceride /(LDL triglyceride + LDL cholesterol ester ) $=0.65$ plasma triglyceride $/(464+$ plasma triglyceride $)$. In vitro transfer of triglyceride from concentrated VLDL to VLDL-depleted plasma produced triglyceride-rich LDL that had similar properties. LDL uptake by HepG2 cells increased with LDL triglyceride content whereas the reverse was found with skin fibroblasts. At $37^{\circ} \mathrm{C}$, the cores of both normal and hypertriglyceridemic LDL were isotropic liquids. Circular dichroic spectra revealed no difference in the secondary structure of normal and triglyceride-rich LDL. The affinity of monoclonal antibody MB47, which binds to the receptor ligand of apo B-100 was independent of LDL triglyceride content. MB3, which binds near residue 1022 of apo B-100, showed a triglyceride-dependent decrease in affinity for LDL from hypertriglyceridemic subjects and from in vitro incubations. LDL with an elevated triglyceride content formed in vitro had reduced proteolytic cleavage of apo B-100 by Staphylococcus aureus V8 protease. From these data, we infer that $(a)$ LDL triglyceride is a predictable function of plasma triglyceride, $(b)$ triglyceride induces subtle changes in apo B-100 structure at a site that is remote from the putative receptor binding ligand, and $(c)$ the triglyceride-dependent receptor-binding determinants of apo B-100 are recognized differently by fibroblasts and HepG2 cells. (J. Clin. Invest. 1993.91:1926-1933.) Key words: atherosclerosis $\bullet$ hypertriglyceridemia $\cdot$ lipoproteins $\bullet$ apolipoprotein B • apo B / E receptor
\end{abstract}

\section{Introduction}

Epidemiological studies have established that premature atherosclerosis is indirectly associated with elevated plasma triglyceride $(1,2)$. Familial hypertriglyceridemia, expressed as several phenotypes, results from an excess of VLDL or chylomicron synthesis. Reduced lipoprotein clearance from the plasma compartment secondary to other disease states, such as diabetes mellitus, chronic renal disease, or obstructive liver dis-

Address correspondence to Barry J. McKeone, The Department of Internal Medicine, Baylor College of Medicine, The Methodist Hospital, MS A601, 6565 Fanin, Houston, TX 77030.

Received for publication 5 August 1992 and in revised form 7 December 1992.

J. Clin. Invest.

(c) The American Society for Clinical Investigation, Inc. 0021-9738/93/05/1926/08 \$2.00

Volume 91, May 1993, 1926-1933 ease, also produces hypertriglyceridemia (3). In vivo the fractional catabolic rate of hypertriglyceridemic LDL in hypertriglyceridemic subjects is faster than that of normal homologous LDL (4), with the primary site for the clearance of intact LDL particles being located on the surface of liver cells (5-7). In spite of the accelerated rate of catabolism, uptake of hypertriglyceridemic LDL in cultured fibroblasts, the most commonly used cell line to model receptor-mediated uptake, is lower than that observed with normal LDL (8).

The core of LDL is one putative source of the lipid deposits in atherosclerotic plaques (9). The LDL particle consists of a hydrophobic core of cholesterol, cholesterol ester, and triglyceride, with a surface composed primarily of amphiphilic phospholipids, cholesterol, and apo B-100, which is the ligand for cell surface receptor-mediated uptake (10-12). Elevated plasma chylomicron and VLDL triglyceride levels increase the triglyceride content of LDL in a process mediated by the action of plasma lipid-transfer proteins $(13,14)$. This in turn produces changes in the physical properties of the particle surface and core (15-18). In this report we describe the effects of elevated plasma triglyceride on the lipid composition and physical properties of LDL from normal and hypertriglyceridemic subjects and its subsequent catabolism by cultured fibroblast and HepG2 cells.

\section{Methods}

Materials. After an overnight fast, plasma was obtained by venipuncture from volunteers from the laboratory staff in Houston and from hypertriglyceridemic patients of the Lipid Clinic in Innsbruck, Austria. The case-control study population was composed of normolipemic subjects and hypertriglyceridemic subjects with a fasting plasma triglyceride $>250 \mathrm{mg} / \mathrm{dl}(3,19)$. Informed consent was obtained from all participants. LDL was isolated by sequential and rate zonal ultracentrifugation (20) in the density range $1.019-1.063 \mathrm{~g} / \mathrm{ml}$. The homogeneity of the isolated LDL was assessed by nondenaturing (2-16\%; Pharmacia LKB Biotechnology Inc., Piscataway, NJ) polyacrylamide gradient gel electrophoresis (21). The apoprotein composition of LDL was based on SDS-PAGE on 4-12\% gradient gels (22). LDL surface charge was evaluated by their mobility on $1 \%$ agarose Universal gels relative to acetylated LDL (Ciba Corning, Palo Alto, CA). Plasma cholesterol, HDL cholesterol, and triglyceride levels were measured using a autoanalyzer (COBAS FARA II; Roche Diagnostics, Montclair, NJ).

LDL triglyceride, total cholesterol, and free cholesterol were determined using enzymatic assay kits from Boehringer Mannheim Diagnostics (Indianapolis, IN). Cholesterol esters were calculated from the difference between total and free cholesterol, multiplied by 1.65 to correct for the presence of the acyl chain (23). LDL protein was determined by the Markwell modification of the Lowry protein assay (24) using BSA as a standard. Acetylated LDL was produced by the method of Basu et al. (25). Transesterification of cholesterol esters isolated by TLC with methanolic $\mathrm{BF}_{3}$ produced methyl esters from which the acyl composition was determined by capillary-column gas liquid chromatography. Fatty acids were identified by comparison of retention times with those of standard mixtures (Nu Check Prep, Inc., Elysian, MN). 
Monoclonal antibodies against apo B-100, MB47, and MB3 were the generous gifts of Dr. Linda Curtiss. Polyclonal anti apo $\mathrm{E}$ was obtained through the Baylor College of Medicine Animal Program.

Experimental procedures. In vitro transfer of triglyceride from concentrated VLDL to LDL was performed as follows: plasma obtained from a unit of fresh normolipidemic blood was mixed with $0.2 \mathrm{U} / \mathrm{ml}$ aprotinin, $175 \mu \mathrm{g} / \mathrm{ml} \mathrm{PMSF}, 50 \mu \mathrm{g} / \mathrm{ml}$ leupeptin, and $5 \mu \mathrm{g} / \mathrm{ml}$ gentamicin (Sigma Chemical Co., St. Louis, MO). It was then centrifuged at $5^{\circ} \mathrm{C}$ to float the VLDL. The top half of the tube, which included the VLDL and the clear zone beneath it, was removed and discarded. Pooled VLDL from several normolipidemic donors was filtered through a $0.45-\mu \mathrm{m}$ filter and concentrated by ultrafiltration at $4^{\circ} \mathrm{C}$. The VLDL was mixed with the 1.006 bottom fraction and incubated at $37^{\circ} \mathrm{C}$ for varying times and at varying VLDL concentrations equivalent to plasma triglyceride concentrations. Samples were removed after incubation at $37^{\circ} \mathrm{C}$ and transferred to an ice bath. The density of each sample was adjusted to $1.019 \mathrm{~g} / \mathrm{ml}$ with solid $\mathrm{KBr}$ and centrifuged overnight at $35,000 \mathrm{rpm}$ at $5^{\circ} \mathrm{C}$. The VLDL was removed, and the infranatant was overlaid with a $1.006 \mathrm{~g} / \mathrm{ml} \mathrm{Kbr}$ solution and centrifuged again at $40,000 \mathrm{rpm}$; the supernatant was discarded. The infranatant was adjusted to a density of 1.063 with solid $\mathrm{Kbr}$ and spun overnight. The LDL obtained was analyzed for triglyceride, cholesterol, cholesterol ester, protein, and size by gel electrophoresis. LDL thermotropic transitions were measured with a Microcal MC-2 differential scanning calorimeter (Northampton, MA). The samples (2-21 mg of LDL-protein dialyzed against Tris-buffered saline, $10 \mathrm{mM}$ Tris, 100 $\mathrm{mM} \mathrm{NaCl}, 1 \mathrm{mM}$ EDTA, and $1 \mathrm{mM} \mathrm{NaN}_{3}, \mathrm{pH} 7.4$ ) were scanned three times at $10^{\circ} \mathrm{C} / \mathrm{h}$.

Apo B-100 secondary structure was estimated using a spectropolarimeter (Model J-500A; Jasco Inc., Tokyo, Japan). LDL ( $100 \mu \mathrm{g} / \mathrm{ml}$ protein) samples dialyzed against $10 \mathrm{mM}$ sodium phosphate $\mathrm{pH} 7.4$ were scanned 10 times from 260 to $184 \mathrm{~nm}$. The averaged scans were baseline corrected, and the relative contributions of alpha helix, beta sheet, beta turn, and random coil were estimated using eigenanalysis and the spectra of peptides of known secondary structure (26).

LDL binding and uptake by the human hepatoma cell line, HepG2, and by human fetal foreskin fibroblasts was measured according to a modification of the method of Goldstein et al. (27). Both cell lines were grown in DME supplemented with $10 \%$ FBS. Each dish was rinsed with PBS and incubated for $48 \mathrm{~h}$ with DME plus 5\% lipoproteindeficient serum (LPDS). ${ }^{1}$ Triplicate samples of radioiodinated LDL in 5\% LPDS in DME buffered with bicarbonate for uptake studies or DME buffered with Hepes for binding studies, plus a second similar series of samples containing both radiolabeled LDL plus $500 \mu \mathrm{g} / \mathrm{ml}$ of unlabeled LDL were incubated with the cells. Before use, all LDL samples were passed through a $0.45-\mu \mathrm{m}$ filter. After incubation the wells were rinsed with three rapid washes of PBS plus $2 \mathrm{mg} / \mathrm{ml} \mathrm{BSA}$, followed by two (10-min) washes with PBS-BSA and a final wash of PBS alone. The dishes were then incubated with $1 \mathrm{ml}$ of sodium dextran sulfate $(4 \mathrm{mg} / \mathrm{ml})$ in $50 \mathrm{mM} \mathrm{NaCl}, 10 \mathrm{mM} \mathrm{Hepes,} \mathrm{pH} \mathrm{7.4,} \mathrm{at} 4^{\circ} \mathrm{C}$ for 1 h. After the dextran sulfate wash was removed and an aliquot was counted to determine cell surface binding, the cells were digested with 1 $\mathrm{ml}$ of $0.1 \mathrm{~N} \mathrm{NaOH}$. Aliquots were removed for protein analysis and radiolabel uptake by gamma counting. All results were corrected for nonspecific binding of LDL to blank wells.

The relative affinities of monoclonal antibodies MB3 and MB47 for LDL apo B-100 were measured by a direct binding assay using a standard ELISA. LDL ( $500 \mathrm{ng}$ ) in standard buffer from each sample was bound to a duplicate series of 12 wells on a 96-well plate overnight at $4^{\circ} \mathrm{C}$. After washing the plates four times with $0.25 \% \mathrm{BSA}$ in PBS and blocking with $3 \%$ BSA in PBS for $1 \mathrm{~h}$, serial dilutions of MB3 and MB47 were made for each of the sample wells. The plates were again incubated overnight at $4^{\circ} \mathrm{C}$ and washed four times the next day with $0.25 \%$ BSA in PBS. The horseradish peroxidase conjugate of goat anti-

1. Abbreviations used in this paper: LPDS, lipoprotein-deficient serum; WR, weight ratio. mouse $\mathrm{IGg}(50 \mu \mathrm{l})$ was then allowed to bind to the LDL-bound monoclonal antibody overnight at $4{ }^{\circ} \mathrm{C}$ and after washing four times with $0.25 \%$ BSA in PBS, $100 \mu$ l of the substrate $0.02 \% 2,2$ Azino-bis (3-ethylbenzthiazoline-6-sulfonic acid), $0.02 \% \mathrm{H}_{2} \mathrm{O}_{2}$, in $0.1 \mathrm{M}$ citric acid pH 4 was added to each well. After $15 \mathrm{~min}$ at room temperature the reaction was stopped with $50 \mu \mathrm{l}$ of $1 \mathrm{M} \mathrm{NaF}$ and the absorption at $410 \mathrm{~nm}$ was measured. Assays for the presence of apo $E$ in vitro incubation experiments were performed as above using goat anti-human polyclonal apo $\mathrm{E}$ antibodies and the horseradish peroxidase conjugate of rabbit antigoat IGg.

Partial proteolytic digestion of LDL-apo B-100 by Staphylococcus aureus V8 protease (Pierce Chemical Co., Rockford, IL) was performed by a modification of the method of Kunitake et al. (28). In vitro hypertriglyceridemic LDL ( $125 \mu \mathrm{g})$ was incubated with $0.33 \mu \mathrm{g}$ of protease for varying amounts of time at $37^{\circ} \mathrm{C}$. The reaction was stopped by the addition of SDS (final concentration $2 \%$ ) and immersion in boiling water for $1 \mathrm{~min}$. The mixture was electrophoresed on a 4-12\% SDS gradient gel and stained with Coomassie brilliant blue R-250. Statistical procedures were performed using the CSS-Statsoft program for personal computers (StatSoft, Inc., Tulsa, OK).

\section{Results}

LDL composition. After an overnight fast, plasma lipid values were determined. As previously reported $(2,4)$, elevated plasma cholesterol $(303.8 \pm 68.4 \mathrm{mg} / \mathrm{dl})($ Table I $)$ and reduced HDL cholesterol $(34.2 \pm 14.0 \mathrm{mg} / \mathrm{dl})$ typify patients with primary hypertriglyceridemia. In hypertriglyceridemic subjects, the mean increases in plasma cholesterol and triglyceride, respectively, were two- and sixfold over normal values. The range of triglyceride levels for the hypertriglyceridemic population $(250-1,938 \mathrm{mg} / \mathrm{dl})$ was characteristic of moderate to severe hypertriglyceridemia.

The weight ratio (WR) of triglyceride in LDL was expressed as $\mathrm{WR}=\mathrm{LDL}$ triglyceride $/(\mathrm{LDL}$ triglyceride $+\mathrm{LDL}$ cholesterol ester). In the hypertriglyceridemic population, the average WR was approximately four times larger than the normal subjects. The relationship between WR and the fasting plasma triglyceride is shown in Fig. $1 A$. The data were fitted to an adsorption isotherm that took the form

$\mathrm{WR}=0.65$ plasma triglyceride $/$

(464 + plasma triglyceride).

Saturation of the isotherm occurred at a triglyceride/(neutral lipid) ratio of 0.65 . To determine if the above isotherm repre-

Table I. Comparative Data for Normal and Hypertriglyceridemic Subjects

\begin{tabular}{lcccc}
\hline \multicolumn{1}{c}{ Parameter } & $n$ & Normolipidemic & $n$ & Hypertriglyceridemic \\
\hline $\begin{array}{l}\text { Plasma cholesterol } \\
(\mathrm{mg} / \mathrm{dl})\end{array}$ & 30 & $198.3 \pm 35.5$ & 48 & $303.8 \pm 68.4^{*}$ \\
$\begin{array}{l}\text { Plasma triglyceride } \\
(\mathrm{mg} / \mathrm{dl})\end{array}$ & 30 & $109.5 \pm 60.9$ & 48 & $731.0 \pm 521.7^{*}$ \\
$\mathrm{WR}^{\S}$ & 24 & $0.126 \pm 0.097$ & 47 & $0.359 \pm 0.176^{*}$ \\
$\begin{array}{l}\text { LDL transition } \\
\text { temperature }\left({ }^{\circ} \mathrm{C}\right)\end{array}$ & 22 & $28.0 \pm 3.1$ & 12 & $21.5 \pm 4.7^{*}$
\end{tabular}

Values are mean $\pm \mathrm{SD} .{ }^{*} P<0.001$ as determined by two-tailed $t$ test for independent samples. ${ }^{\ddagger} P<0.001$ as determined by MannWhitney $U$ test. ${ }^{\S} \mathrm{WR}=\mathrm{LDL}$ triglyceride/(LDL triglyceride $+\mathrm{LDL}$ cholesterol ester). 

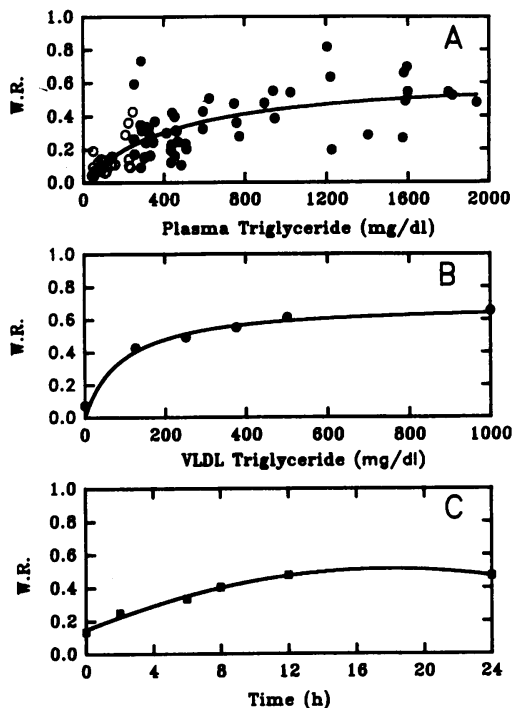

Figure 1. LDL triglyceride composition as a function of plasma triglyceride level. $(A)$ Data obtained from the casecontrol study population were fitted to an absorption isotherm; $\mathrm{WR}=0.65$ plasma triglyceride /(464 + plasma triglyceride). The filled circles represent hypertriglyceridemic patients whereas the open circles represent normolipidemic subjects. $(B)$ Equilibrium isotherm for LDL incubated $48 \mathrm{~h}$ in vitro at $37^{\circ} \mathrm{C}$ with VLDL at increasing concentrations. The isotherm fitted to the data was $\mathrm{WR}=0.70$ plasma triglyceride/ $(91+$ plasma triglyceride $)$. $(C)$ Time-dependent increase in LDL triglyceride/neutral lipid ratio when VLDL concentration is 1,000 $\mathrm{mg} / \mathrm{dl}$. Saturation occurred by $18 \mathrm{~h}$ and at a WR of 0.56 .

sents an equilibrium triglyceride concentration in LDL, we have attempted to duplicate it in vitro by adding VLDL in increasing concentration to plasma from which the VLDL had been removed and incubating it at $37^{\circ} \mathrm{C}$ for $48 \mathrm{~h}$. The isotherm thus obtained (Fig. $1 B$ ) fit the following equation:

$\mathrm{WR}=0.70$ plasma triglyceride $/$

$(91+$ plasma triglyceride $)$.

Saturation occurred at a similar triglyceride /( neutral lipid) ratio 0.70 versus 0.65 , however, the value for the dissociation constant ( 91 vs. $464 \mathrm{mg} / \mathrm{dl}$ ) was approximately one fourth that observed in the patient study. Protein-mediated transfer of triglyceride in vitro produces a time-dependent increase in LDL triglyceride/neutral lipid ratio (Fig. $1 C$ ). The saturation value of 0.56 at $24 \mathrm{~h}$ was similar to that seen in both the case-control study and the in vitro incubation. The half-time, $t_{1 / 2}$, for the transfer was $\sim 6 \mathrm{~h}$.

Table II contains the average fatty acid composition of the LDL cholesterol esters in normal and hypertriglyceridemic subjects. There were two minor differences. First, as indicated by the greater standard deviations of the fatty acid compositions, the hypertriglyceridemic group was more heterogeneous. Second, in the hypertriglyceridemic group, the stearate and ar-

Table II. LDL-Cholesterol Ester Fatty Acid Composition

\begin{tabular}{crc}
\hline Fatty acid & Normolipidemic & Hypertriglyceridemic \\
\hline$\%$ & & \\
C14:0 & & \\
C16:0 & $1.58 \pm 0.67$ & $1.75 \pm 2.41$ \\
C16:1 & $10.85 \pm 1.52$ & $15.42 \pm 4.44$ \\
C18:0 & $3.03 \pm 0.80$ & $4.11 \pm 2.14$ \\
C18:1 & $3.98 \pm 2.75$ & $2.11 \pm 1.26$ \\
C18:2 & $23.89 \pm 1.94$ & $27.54 \pm 8.39$ \\
C20:4 & $44.85 \pm 2.50$ & $43.28 \pm 12.65$ \\
& $8.22 \pm 2.21$ & $4.66 \pm 2.81$ \\
\hline
\end{tabular}

achidonate contents were lower whereas those of oleate and palmitate were elevated.

Functional assays of normal and hypertriglycerdemic $L D L$. The uptake of LDL and hypertriglyceridemic LDL by cell surface receptors was tested in two model systems that were selected because they are representative of the kinds of cells that are found in hepatic and peripheral tissues; these were, respectively, the human hepatoma cell line, HepG2, and human skin fibroblasts derived from the preputial tissue of normal subjects. HepG 2 cells have been shown to be a suitable model system for the study of hepatocytic lipoprotein metabolism by a number of authors (29-31). The binding of normal and hypertriglyceridemic LDL was compared (Table III). The data from the fibroblasts confirmed the observations of Aviram et al. (8), who reported that the uptake of hypertriglyceridemic LDL to fibroblasts was lower than that of normal LDL. In contrast, our data with HepG2 cells showed that in this cell line the uptake of hypertriglyceridemic LDL was greater than that of normal LDL. We then selected a subset of four subjects from the clinical data group that had WR ranging from 0.10 to 0.50 and performed LDL receptor saturation studies using HepG2 cells (Fig. $2 A$ ). The lower curve represents the difference between total LDL uptake and nonspecific uptake by the cells. Receptor uptake increased with amount of LDL and saturated the receptor at $\sim 250 \mu \mathrm{g} / \mathrm{ml}$. LDL with $\mathrm{WR}=0.50$ and 0.30 were taken up to a greater extent than LDL with WR $=0.19$ or 0.10 (Fig. $2 B$ ).

Native normal and hypertriglyceridemic LDL structures. On the basis of circular dichroic criteria, the secondary structures of normal LDL and hypertriglyceridemic LDL having a range of WR extending from 0.10 to 0.73 was indistinguishable; the calculated secondary structures were alpha-helix $(24 \pm 5.2 \%)$, beta sheet $(28 \pm 3.9 \%)$, beta turn $(23 \pm 1.1 \%)$, and random coil $(24 \pm 1.7 \%)$.

Nondenaturing gradient gel electrophoresis of normal and hypertriglyceridemic LDL usually resulted in two bands corresponding to $\mathrm{LDL}_{1}$ and $\mathrm{LDL}_{2}$; however, the hypertriglyceridemic LDL (data not shown) displayed somewhat greater electrophoretic mobility than that from normolipidemic plasma. The liquid crystal to isotropic liquid transitions of 22 normal and 12 hypertriglyceridemic subjects were measured by differential scanning calorimetry.

Melting temperatures were determined from the midpoint of excess heat capacity endotherms (Fig. $3 C$ ). The average melting temperature of the LDL obtained from the hypertriglyceridemic subjects was $\sim 6.5^{\circ} \mathrm{C}$ lower than that of the nor-

Table III. Receptor Uptake of Normal and Hypertriglyceridemic LDL by HepG2 Cells and Fibroblast**

\begin{tabular}{lcc}
\hline \multicolumn{1}{c}{ Cell type } & Low weight ratio & High weight ratio \\
\hline & \multicolumn{2}{c}{$n g / m g$} \\
Human skin fibroblasts & $288 \pm 70$ & $101 \pm 57$ \\
HepG2 cells & $98 \pm 4$ & $280 \pm 83$ \\
& & \\
\hline
\end{tabular}

* Comparison of hypertriglyceridemic LDL uptake at $37^{\circ} \mathrm{C}$ by human fetal foreskin fibroblasts vs. HepG2 cells. ${ }^{125} \mathrm{I}$-labeled LDL $(100 \mu \mathrm{g} /$ $\mathrm{ml}$ ) from two subjects with low (0.10) and high (0.30) LDL WRs were incubated with $75-80 \%$ confluent cells and incorporation of LDL into $\mathrm{NaOH}$ digests of the cells was measured. The values shown are the means \pm SD of three replicates corrected for nonspecific uptake. 

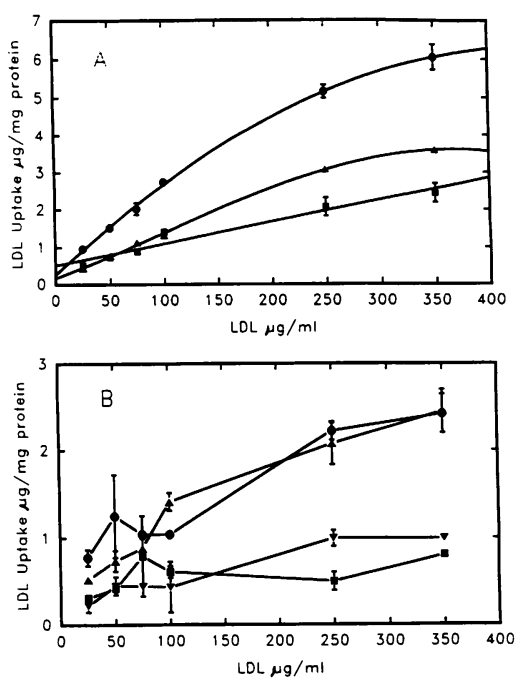

Figure 2. LDL uptake by $\mathrm{HepG} 2$ cells at $37^{\circ} \mathrm{C}$. Monolayers of $75-80 \%$ confluent cells preincubated for $24 \mathrm{~h}$ with LPDS media, and then incubated for $5 \mathrm{~h}$ with $25,50,75,100,200$, and $350 \mu \mathrm{g} / \mathrm{ml}$ of ${ }^{125} \mathrm{I}$ labeled LDL to determine total LDL uptake $(\bullet)$ and low affinity binding ( $\square$ ) measured, using the above concentrations of radiolabeled LDL plus $500 \mu \mathrm{g} / \mathrm{ml}$ of unlabeled LDL $(A)$. After extensive washing to remove surfacebound LDL, aliquots of $0.1 \mathrm{M} \mathrm{NaOH}$ cell digests were counted in a gamma counter, while another aliquot was assayed for protein content. The results were expressed as $\mu \mathrm{g}$ of LDL uptake/mg cell protein. High affinity uptake (ム) was determined as the difference between total and low affinity uptake. All results were corrected for nonspecific binding of LDL to blank wells. Each point represents the average of three determinations. High affinity $(B)$ uptake of LDL from four subjects with WR $=0.10(\nabla), 0.19(\bullet), 0.30(\Delta)$, and $0.50(\bullet)$ to assay the effect of excess LDL triglyceride content upon receptor mediated uptake of LDL.

mals ( Table I). However, in all cases the melting temperatures were below $37^{\circ} \mathrm{C}$. The LDL melting temperatures correlated with the plasma triglyceride LDL levels of the donor, with the melting temperatures decreasing as plasma triglyceride increased (Fig. $3 A$ ). LDL melting temperatures correlated with triglyceride content but were independent of cholesterol ester fatty acyl chain composition. An increase in the WR produced a linear decrease in LDL melting temperature (Fig. $3 B$ ), as described by the equation
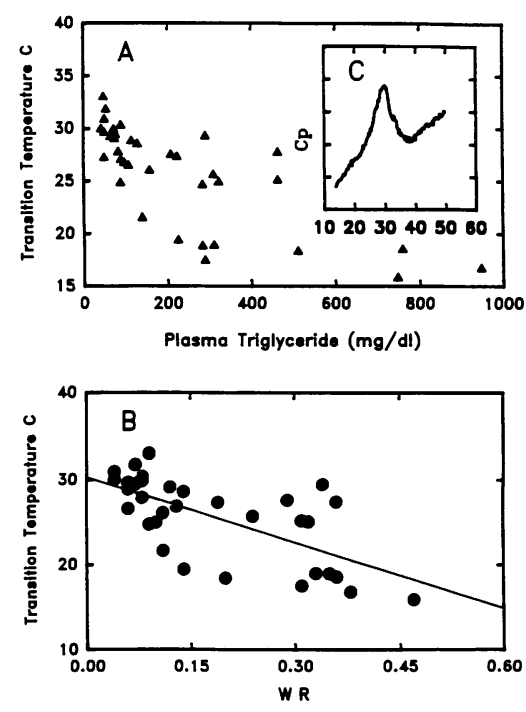

Figure 3. LDL cholesterol ester smectic to isotropic transition temperature as a function of triglyceride content. Increasing plasma triglyceride produces a curvilinear decrease $(A)$ in LDL transition temperature whereas LDL triglyceride effects a linear decrease in transition temperature with increasing triglyceride content $(B)$. The linear regression line is described by $T \mathrm{c}=30.27$ $-26.34 \times \mathrm{WR}, r$ $=-0.68$. The data shown is a combination of normal and hypertri-

glyceridemic LDL for which measurable transitions were obtained. The transition temperature was determined from the midpoint of the excess heat capacity curves $(C)$.
$T_{\mathrm{c}}=30.3-26.3 \mathrm{WR}$

The width of the transitions increased with increasing triglyceride content and, in some cases of severe hypertriglyceridemia, the endotherms were too broad to permit accurate quantification of the melting temperature. For the 34 subjects that are plotted in Fig. $3 B$, the correlation coefficient was -0.68 .

Structure and properties of in vitro hypertriglyceridemic $L D L$. To characterize the structure-function relationships that distinguish the hepatocellular uptake of LDL and hypertriglyceridemic LDL, the latter were formed in vitro by using the lipid transfer activity of human plasma as a mediator of transport of triglyceride from an excess of VLDL to LDL. Over a 24-h time interval, the WR increased from an initial value of 0.10 to 0.56 (Fig. $4 A$ ) for VLDL. The calculated limit of WR at $t=$ infinity was 0.62 . The fivefold change in WR was similar to the range that was observed in the plasma LDL of our sample population. The increase in the triglyceride content of the LDL produced similar effects on the thermotropic behavior of the in vitro hypertriglyceridemic LDL that were observed in the native LDL of the sample population. The increase in the triglyceride content was accompanied by a continuous reduction in the transition temperature from 25 to $-2.5^{\circ} \mathrm{C}$, the last value being obtained by extrapolation of the data to $24 \mathrm{~h}$ (Fig. $4 A$ ).
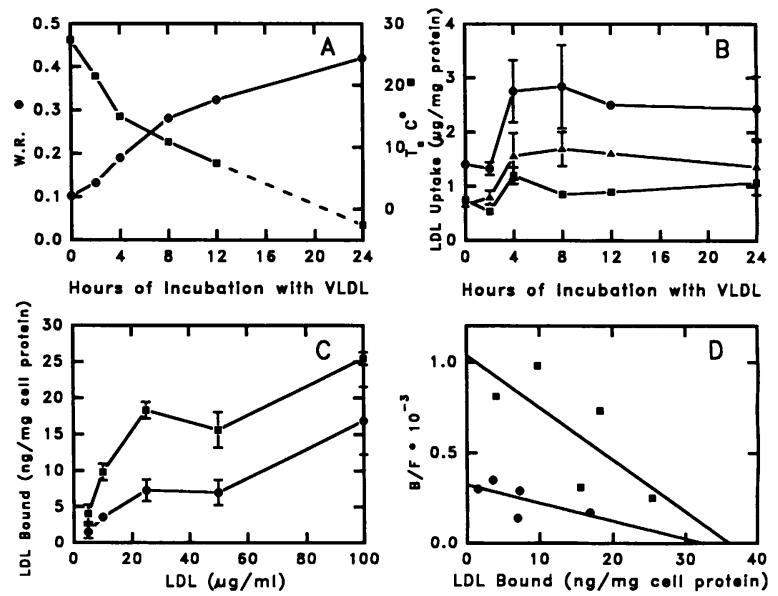

Figure 4. Changes in the triglyceride content, melting temperature, and hepatocellular receptor-mediated binding and uptake of in vitro hypertriglyceridemic $\mathrm{LDL}$ produced by incubation at $37^{\circ} \mathrm{C}$ with an excess of VLDL. $(A)$ VLDL-TG $(\bullet)$ transfers via a cholesterol ester transfer protein in the 1.006 bottom fraction to produce an increase in LDL triglyceride content as a function of time. Upon incorporation of VLDL triglyceride into the LDL particle core, the cholesterol ester smectic phase is ( $\square$ ) disrupted producing a decrease in cholesterol ester liquid crystalline to isotropic transition temperature. The dotted line is an extrapolation of the data to the 24-h time point. $(B)$ Internalization of ${ }^{125} \mathrm{I}$-radiolabeled LDL ( $100 \mu \mathrm{g} / \mathrm{ml}$ LDL protein $)$, after $5 \mathrm{~h}$ of incubation with in vitro triglyceride-rich LDL from the above incubation, by HepG 2 cells increases with LDL triglyceride content. The data shown in $B$ is the average of three replicates for the total uptake $(\bullet)$, nonspecific uptake $(\bullet)$, and the difference or receptormediated uptake $(\Delta)$. $(C)$ Binding of LDL with WRs of $0.05(\bullet)$ or 0.53 (ש) to HepG2 cells at $4^{\circ} \mathrm{C}$. Elevated cell-specific binding of in vitro triglyceride-rich $L D L$ to the $L D L$ receptor after a 2 -h equilibration period. $(D)$ Scatchard transformation of data in $C$ with WRs of $0.05(\bullet)$ or $0.53(\bullet)$. All of the data shown is an average of three replicates. 
No lipolytic activity was present in our in vitro incubations, therefore, the production of small dense LDL particles through the lipolysis of triglyceride-rich LDL that is observed in vivo in hypertriglyceridemia did not occur. This was verified by nondenaturing gel electrophoresis in which the in vitro hypertriglyceridemic LDL was distributed into two subfractions, $\mathrm{LDL}_{1}$ and $\mathrm{LDL}_{2}$, which exhibited the same electrophoretic mobilities as those of their respective counterparts before enrichment with triglyceride. The average particle size was $26.75 \pm 0.91 \mathrm{~nm}$. SDS-PAGE analysis of the in vitro hypertriglyceridemic LDL revealed a single band corresponding to that of apo B-100; no other protein band was found, even where the gels were greatly overloaded. Immunochemical assays for the presence of apo $E$ were also negative.

With HepG2 cells there was enhanced receptor specific uptake of in vitro hypertriglyceridemic LDL (Fig. $4 \mathrm{~B}$ ) that increased with the triglyceride content of the particle. This occurred where the particle melting temperature decreased from $>25$ to $<0^{\circ} \mathrm{C}$. Therefore, receptor binding was independent of the physical state of the lipid at $37^{\circ} \mathrm{C}$, which was that of an isotropic liquid. Similar results were obtained for LDL degradation (data not shown) and in equilibrium binding to the receptor at $4^{\circ} \mathrm{C}($ Fig. $4 \mathrm{C})$. LDL with a tenfold increase in WR $(0.05$ vs. 0.53 ) displayed greater saturation binding to the cell surface. The dissociation constants as determined by Scatchard analysis were $21 \mu \mathrm{g} / \mathrm{ml}$ for the low triglyceride LDL versus 28 $\mu \mathrm{g} / \mathrm{ml}$ for the hypertriglyceridemic LDL (Fig. $4 D$ ), while the maximum amount of LDL bound was $32 \mathrm{ng} / \mathrm{mg}$ cell protein for low WR LDL versus $37 \mathrm{ng} / \mathrm{mg}$ protein for the hypertriglyceridemic LDL.

The association of a monoclonal antibody (MB47) that binds to apo B-100 at a site that inhibits binding to the LDL receptor with in vitro hypertriglyceridemic LDL was measured. Over a wide range of WR, the binding of this antibody was independent of the triglyceride content of the in vitro hypertriglyceridemic LDL (Fig. $5 \mathrm{~B}$ ). Similar data (not shown) were obtained for the four subjects whose LDL were used for the receptor uptake experiments.

In contrast, the association of $\mathrm{MB} 3$ with apo $\mathrm{B}-100$ varied with the triglyceride content of the particle (Fig. $5 \mathrm{C}$ ). Increasing amounts of triglyceride produced a decreased affinity of the antibody for the epitope on apo B-100 surface. The negative correlation between LDL triglyceride and the binding of MB3 to LDL was also found in LDL from the subset of the study population used in the HepG2-uptake experiments (Fig. $5 \mathrm{~A}$ ). The lone exception to this correlation may be due to apoprotein heterogeneity (32), however, since the in vitro hypertriglyceridemic LDL was obtained from a single subject, apoprotein heterogeneity may be ruled out as the cause of differential MB3 binding.

In vitro triglyceride-enhanced LDL exhibited increased particle migration on agarose gels. The mobility relative to that of acetylated LDL increased in a time-dependent fashion and nearly doubled as the WR rose from 0.05 to 0.53 (Fig. $6 \mathrm{~B}$ ). Incubation times of up to $48 \mathrm{~h}$ produce LDL that increase in negative charge but never equal that of acetylated LDL.

Independent verification of triglyceride-induced alteration of apo B-100 tertiary structure was obtained by partial proteolytic digestion of in vitro hypertriglyceridemic LDL by $S$. aureus V8 protease (Fig. $6 \mathrm{~A}$ ). Control LDL samples that were incubated with VLDL very briefly before ultracentrifugation (lanes 1-4) were far more susceptible to proteolytic digestion than those that had been incubated for $24 \mathrm{~h}$ (lanes 5-8). In the
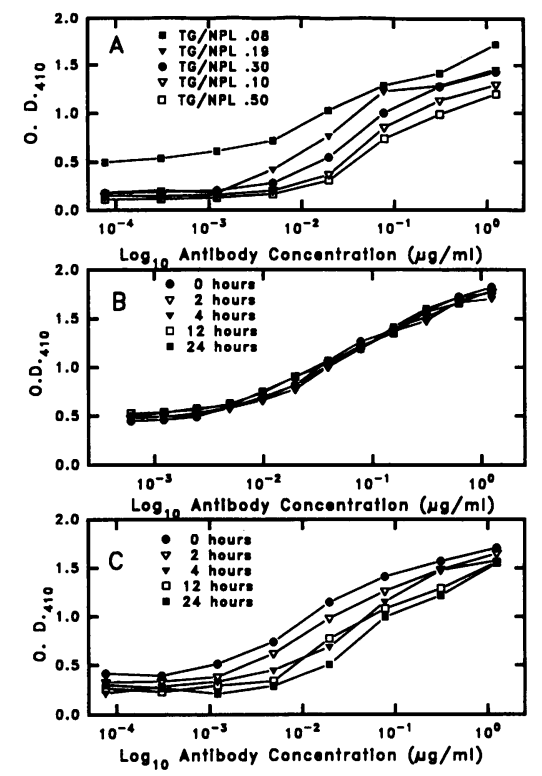

Figure 5. Direct binding assays of monoclonal antibodies MB3 and MB47 association with LDL. $(A) \mathrm{LDL}$ ( $500 \mathrm{ng}$ per well) from the four clinical subjects with varying WR used for the uptake experiments in Fig. $2 B$ plus a control were titrated with serial dilutions of MB3. With the exception of the sample with a WR of $0.10(\nabla)$, the samples in $A$ display a progressive decrease in affinity for MB3 as the triglyceride in nonpolar lipid ratio increased; 0.08 $(\bullet), 0.19(\nabla), 0.30(\bullet)$, and $0.50(\square) .(B)$ Bind-

ing of MB47 to the receptor-binding region of apo B-100, on LDL (500 ng per well) from $0-(\bullet), 2-(\nabla), 4-(\nabla), 12-(\square)$, and 24- $(\square) h$ incubations with concentrated VLDL. The data show there was little variation in the ability of the antibody to bind to the highly conserved receptor-binding ligand. $(C) \mathrm{LDL}$ from the in vitro incubation of LDL with concentrated VLDL display a time-dependent decrease in MB3 affinity with increasing incubation time. Samples that had been incubated with VLDL (final concentration $1,000 \mathrm{mg} / \mathrm{dl}$ ) for $0-(\bullet)$, 2- $(\nabla), 4-(\nabla), 12-(\square)$, and 24- $(\square) h$ show a progressive shift in the midpoint of the titration curve.

control samples, partial digestion produced a pair of bands at $\sim 205 \mathrm{kD}$ and another major band at $\sim 120 \mathrm{kD}$. The in vitro hypertriglyceridemic LDL showed very little fragmentation even after $90 \mathrm{~min}$ of incubation with the protease. It appears that the exchange of cholesterol ester for triglyceride produces a change in apo B-100 conformation or accessibility that is independent of LDL particle size.

\section{Discussion}

Plasma triglyceride determines $L D L$ core composition and melting properties in a predictable way. Clinical assessment of lipoprotein status typically includes the determination of fasting plasma triglyceride levels. Although no quantitative model was proposed, a logarithmic correlation between LDL triglyceride and fasting triglyceride levels has been reported (13). Analysis of the correlation between plasma triglyceride and LDL triglyceride content led to a quantitative predictive model (Fig. 1 $A$, Eq. 1). There is considerable scatter in the data, but this is probably due to transient daily fluctuations in the plasma triglyceride levels ( 33 ) and not those of LDL triglyceride content. Our data were fitted to an adsorption isotherm in which the asymptote corresponds to WR $=0.65$ (Fig. $1 \mathrm{~A}$ ). Our efforts to duplicate conditions within the plasma compartment in vitro produced an isotherm with a similar saturation WR $(0.70)$ but differing in $K_{\mathrm{d}}, 91$ versus $464 \mathrm{mg} / \mathrm{dl}$ for the cross sectional study (Fig. $1 B$, Eq. 2). In vitro the system was allowed to come to equilibrium, Fig. $1 C$ demonstrates that in vitro LDL triglyceride saturation occurs at $\sim 18 \mathrm{~h}$ of constant mixing with VLDL and that LDL triglyceride content is due to protein-mediated exchange. In the plasma compartment LDL triglyceride content is the net result of steady state kinetics due to three 

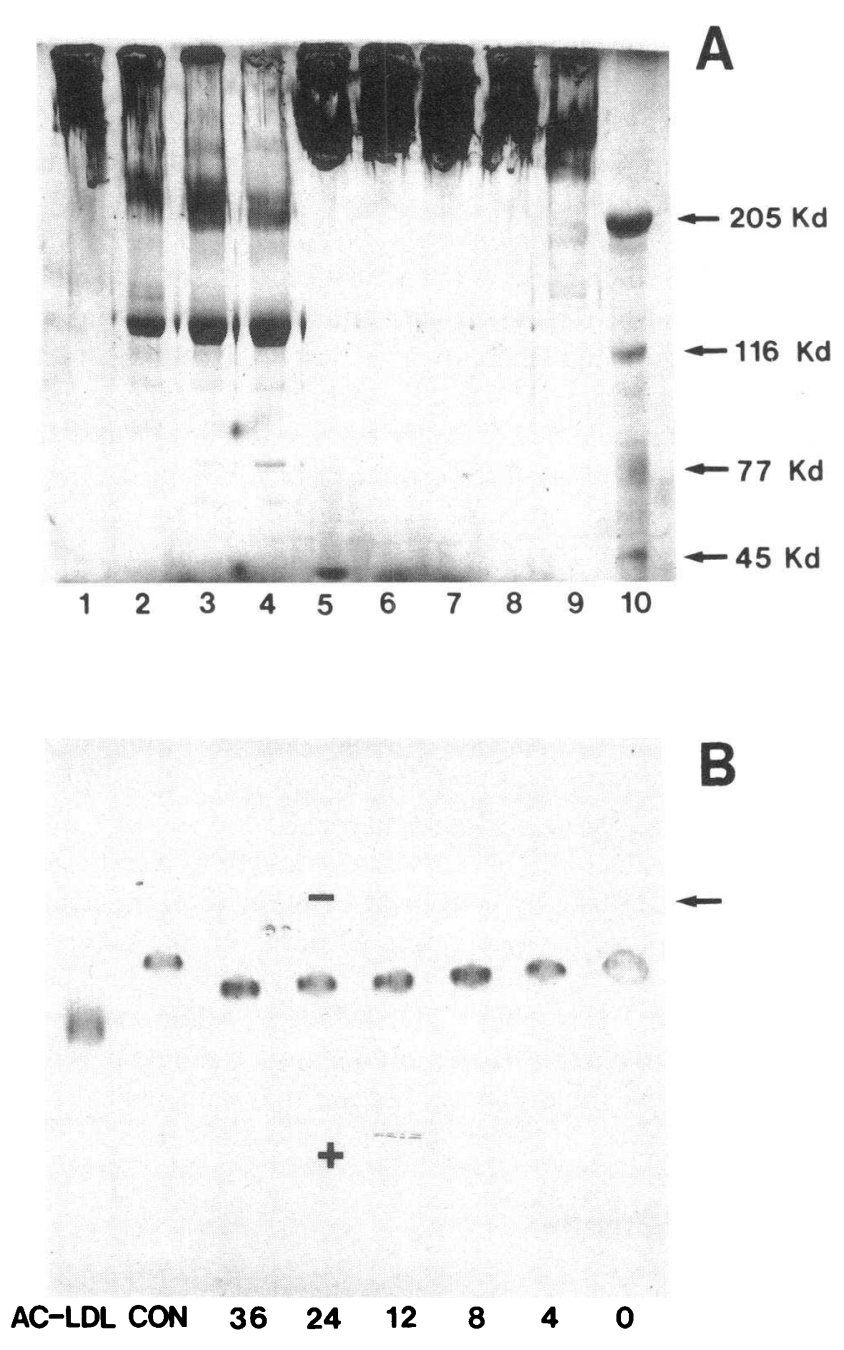

\section{Hours of incubation with VLDL}

Figure 6. Increased LDL triglyceride content alters apo B-100 conformation and LDL particle charge. $(A)$ Time-dependent proteolytic digestion of in vitro hypertriglyceridemic LDL by $S$. aureus V8 protease. LDL from control (lanes 1-4) and 24-h incubations with concentrated VLDL (lanes 5-8) were subjected to proteolytic digestion at $37^{\circ} \mathrm{C}$ for $0,15,45$, and $90 \mathrm{~min}$. Lane 9 is control LDL without protease added and lane 10 contains molecular weight standards of $205,116,77$, and $45 \mathrm{kD}$. (B) Increased agarose gel electrophoretic mobility of LDL with incubation time with $1,000 \mathrm{mg} / \mathrm{dl}$ VLDL at $37^{\circ} \mathrm{C}$. Acetylated LDL $(A C-L D L)$ that does not bind to the LDL receptor was used as a standard whereas LDL that was not incubated with VLDL served as a control $(C O N)$.

other competing processes $(34,35)$. First, VLDL is constantly being removed with a half-time of $\sim 4 \mathrm{~h}$. Secondly, interconversion of VLDL to LDL is also occurring with a mean conversion time of $\sim 12 \mathrm{~h}(36)$. Finally, LDL removal proceeds with a half-time of $\sim 1.6 \mathrm{~d}$ in hypertriglyceridemics and $2.0 \mathrm{~d}$ in normolipidemics (37). The removal of the source of transferable material (VLDL) and the dilution of the plasma LDL pool with newly converted VLDL should shift the dissociation constant in vivo toward higher VLDL concentrations. The slower rate of removal of $L D L$ relative to the above processes explains why the saturation values were similar. If all cholesterol ester and triglyceride in plasma were exchanged to equilibrium, the asymptotes in Figs. $1 A$ and $B$ should approximate that of VLDL, the major triglyceride pool in fasting plasma. These values are slightly less than that of VLDL, which is typically between 0.6 and 0.9 , with an average value being $0.8(38,39)$. The slight difference between the measured ratio for LDL and the observed value for VLDL may be due to intrinsic differences in the affinities of LDL and VLDL for triglyceride and cholesterol ester (40).

The calorimetric data correlate with plasma triglyceride levels (Fig. $3 \mathrm{~A}$ ) and the triglyceride content of LDL (Figs. $3 \mathrm{~B}$ and $4 \mathrm{~A}$ ); the melting temperature decreases with both increasing plasma triglyceride and WR values. This behavior was similar for both native and in vitro LDL. Phase diagrams of triglyceride and cholesterol ester predict that if the neutral lipids of LDL are confined to a common domain, the melting temperature will decrease with increasing triglyceride content (41). At $37^{\circ} \mathrm{C}$, the cores of both native and hypertriglyceridemic LDL are in a melted state. Therefore, the differences in the binding of normal LDL and hypertriglyceridemic LDL to cells was not a function of the physical state of the neutral lipid core. Moreover, the intracellular metabolism of the neutral lipids in the LDL of the normal and hypertriglyceridemic subjects should not differ greatly $(42,43)$.

Functional alterations of hypertriglyceridemic $L D L$. Our data (Table III) confirm the previous reports of reduced uptake of LDL derived from hypertriglyceridemic subjects in fibroblast culture $(8,44)$. In contrast, with HepG2 cells there was enhanced uptake of native and in vitro hypertriglyceridemic LDL (Figs. $2 B$ and $4 B$ ). There are two reasons for these observed differences. First, there are cell-specific differences in the LDL receptor that are due to either changes in receptor number or modification of the receptor itself. The LDL receptor in hepatocytes, HepG2 cells, and fibroblasts appears to be the same $130-\mathrm{kD}$ protein (45), however, the HepG2 receptor has a 10 -fold higher dissociation constant $(\sim 20 \mathrm{vs.} 2 \mu \mathrm{g} / \mathrm{ml})$ than the skin fibroblasts (46). HepG2 cells also have higher absolute levels of LDL receptor mRNA than fibroblasts, but both cell lines show a similar degree of upregulation in response to LPDS (47). However, in HepG2 cells the receptor number is differentially increased relative to the receptor number in fibroblasts in response to several stimuli such as taurine, estrogen, and high density lipoproteins, all of which are believed to increase LDL receptor synthesis by depleting the cells of cholesterol $(46,48,49)$. HepG2 cells also respond to a plasma component that stimulates receptor synthesis without a corresponding cellular cholesterol depletion whereas fibroblasts are unresponsive (50). Morphological data suggests that the hepatocytic receptor differs from that of the fibroblast in that it is diffusely distributed along the sinusoidal microvilli rather than concentrated primarily in coated pits (51). This may explain why binding is independent of particle size in HepG2 cells (52). Recently, Pathak et al. (53) showed in transgenic mice that sorting of LDL receptors to the cell surface is tissue specific and that targeting of the receptor to the hepatocyte basolateral surface is determined by residues $812-828$ in the cytoplasmic domain of the receptor (54). Finally, the LDL receptor protein itself has been shown to exhibit local variation in affinity for LDL (55).

Second, there are structural differences between normal LDL and hypertriglyceridemic LDL that are associated with differential binding to fibroblasts and HepG2 cells. Since it is known that the LDL found in hypertriglyceridemic subjects is smaller than that of normal LDL, size may be a determinant of apo B-100 structure. However, the LDL formed by the in vitro incubation of LDL with excess VLDL in the absence of lipo- 
lytic activity was unchanged in size but exhibited the same dose-dependent changes in binding to the $B / E$ receptor on HepG2 cells (Fig. $4 B$ ) that were seen in LDL isolated from hypertriglyceridemic subjects (Fig. $2 B$ ). Additionally, the in vitro incubation of VLDL with LDL from a single donor demonstrates that the differential LDL uptake was not the result of apo B-100 polymorphism, which may have occurred in LDL obtained from the case-control study population (32).

There could be differences in the amount of apo E associated with normal and hypertriglyceridemic LDL. However, neither gradient gel electrophoresis nor immunochemical assays detected any increase in apo $\mathrm{E}$ content with incubation time. Vega and Grundy (37) found that patients with familial dyslipoproteinemia had high fractional catabolic rates for hypertriglyceridemic LDL, even though they possessed the apo E2/E2 phenotype, which has a low LDL receptor affinity.

The most likely explanation for the differential uptake of normal LDL and hypertriglyceridemic LDL is that increased LDL triglyceride directly affects the tertiary structure or environment of apo B-100 independent of the size of the LDL. The triglyceride-induced changes alter apo B-100 affinity toward the LDL receptor, producing increased uptake by HepG 2 cells and reduced uptake by fibroblasts. Aviram et al. (8) reported that increased triglyceride content of LDL produced alterations in surface accessibility of apo B-100 lysine residues and decreased fibroblast and macrophage uptake of the particle. This seems the most likely explanation for the increased electrophoretic mobility on agarose gels. Triglyceride-rich LDL shows decreased affinity for the LDL receptor whereas acetylated LDL, in which most of the positively charged lysine residues are derivatized, shows almost no affinity for the fibroblast LDL receptor. Since there was no detectable difference between the circular dichroic spectra of normal and hypertriglyceridemic LDL, the conformational differences must be rather small. Additionally, it must be remembered that both electrophoretic mobility and ellipticity are the result of net particle charge and peptide bond absorption, respectively. Further verification of this phenomenon is seen in studies $(56,57)$ of a point mutation in apo B-100 where an arginine at residue 3500 was replaced by a glutamine. The LDL that contain this mutation have reduced accessibility of the lysines and reduced binding to cultured fibroblasts but no spectroscopically detectable alterations in the apo B-100 secondary structure.

Two lines of evidence suggest that the structural difference between normal LDL and hypertriglyceridemic LDL does not involve the putative receptor ligand in a direct way. First, the binding of MB47 to LDL, which is known to bind apo B-100 at or near its receptor-binding domain, was independent of triglyceride content. In contrast, the difference in the binding of monoclonal antibody MB3, which binds near residues 10221031 (28) to normal and hypertriglyceridemic LDL, suggests that there are functionally important triglyceride-dependent structural changes in a region of apo B-100 that is remote from the highly conserved receptor ligand site $(58,59)$, which may in turn alter the affinity of hypertriglyceridemic LDL for the $B / E$ receptor. Second, our data from in vitro production of hypertriglyceridemic LDL suggests that the conformation or accessibility of apo B-100, induced by the substitution of triglyceride for cholesterol ester, obscures the $S$. aureus V8 proteolytic site that is close to the binding site of MB3. According to Kunitake et al. (28), who demonstrated preferential proteolytic cleavage of an apo B-100 fragment in the triglyceride-rich LDL of patients with Tangier disease, this site is located at residue 1076 (Fig. 6). Although this site may be spatially distant from the putative receptor-binding residues 3345-3381 in the apo B-100 primary structure, it may be near the receptor ligand on the LDL surface topology because of folding of the protein $(60,61)$.

Metabolism of normolipidemic $L D L$ and hypertriglyceridemic $L D L$. The differences in the regulation and structure of the $B / E$ receptors of cells of hepatic and nonhepatic origin are important to our understanding of how triglyceride content regulates LDL turnover. Our data quantifies the expected rise in LDL triglyceride with plasma triglyceride levels, and the major functional effect of the change in LDL composition is a subtle change in the structure or accessibility of a region of the LDL remote from the receptor region. If HepG2 cells are a suitable model for the uptake of LDL by the liver, the major site for the turnover of LDL in humans, one would expect the rate of turnover of hypertriglyceridemic LDL to be greater than that of normal LDL. In support of this, Vega and Grundy (37) reported that the turnover of hypertriglyceridemic LDL is $22 \%$ faster than that of normal LDL. In this context it seems likely that if peripheral tissue, for which fibroblasts are a model, were of importance, the LDL turnover rates would be slower. In fact, if there is less uptake by peripheral tissue in vivo, the actual increase in uptake by liver would exceed even the observed value of $22 \%$. This information should be useful in understanding how diet and drugs alter LDL catabolism. Additional turnover data in humans or suitable animal models should demonstrate the relative importance of hepatic and nonhepatic tissue in LDL catabolism in hypertriglyceridemic subjects.

\section{Acknowledgments}

We thank Susan Kelly for providing the line drawings and Georgia White for collecting plasma samples. The technical assistance of Isa Hauser and Gabriele Tröbinger is appreciated.

This work is supported by a grant from the National Institute of Health, HL-2734 1; and a Specialized Center of Research in Arteriosclerosis, HL-27341; and by a grant S46/06 from the Austrian Fond zur Forderung der wissenschaftlichen Forschung.

\section{References}

1. Gotto, A. M. 1988. Etiology, diagnosis, and treatment of the lipid transport disorders. Prog. Cardiol. 16:23-49.

2. Blum, C. B., and R. I. Levy. 1989. Current therapy for hypercholesterolemia. JAMA (J. Am. Med. Assoc.). 261:3582-3587.

3. The Expert Panel. 1988. Report of the national cholesterol education panel on detection, evaluation, and treatment of high blood cholesterol in adults. Arch. Intern. Med. 148:36-69.

4. Vega G. L., and S. H. Grundy. 1990. Primary hypertriglyceridemia with borderline high cholesterol and elevated apolipoprotein B concentrations. Comparison of gemfibrozil vs lovastatin therapy. JAMA (J. Am. Med. Assoc.). 264:2759-2763.

5. Kovanen, P. T., M. S. Brown, and J. L. Goldstein. 1979. Increased binding of low density lipoprotein to liver membranes from rats treated with $17 \alpha$-ethinyl estradiol. J. Biol. Chem. 254:11367-11373.

6. Brown, M. S., P. T. Kovanen, and J. L. Goldstein. 1979. Receptor-mediated uptake of lipoprotein-cholesterol and its utilization for steroid synthesis in the adrenal cortex. Recent Prog. Horm. Res. 35:215-257.

7. Bilheimer, D. W., J. L. Goldstein, S. C. Grundy, T. E. Starzl, and M. S. Brown. 1984. Liver transplantation to provide low-density-lipoprotein receptors and lower plasma cholesterol in a child with homozygous familial hypercholesterolemia. N. Engl. J. Med. 311:1658-1664.

8. Aviram, M., S. Lund-Katz, M. C. Phillips, and A. Chait. 1988. The influence of the triglyceride content of low density lipoprotein on the interaction of apolipoprotein B-100 with cells. J. Biol. Chem. 263:16842-16848.

9. Small D. M. 1988. Progression and regression of atherosclerotic lesions: insights from lipid physical biochemistry. Arteriosclerosis. 8:103-129.

10. Morrisett, J. D., R. L. Jackson, and A. M. Gotto. 1977. Lipid-protein interactions in the plasma lipoproteins. Biochem. Biophys. Acta. 472:93-133. 
11. Goldstein, J. L., and M. S. Brown. 1989. Familial hypercholesterolemia. In The Metabolic Basis of Inherited Disease. C. R. Scriver, A. L. Beaudet, W. S. Sly, and D. Valle, editors. McGraw-Hill, New York. 1215-1250.

12. Mahley, R. W., and S. C. Rall. 1989. Type III Hyperlipoproteinemia (Dysbetalipoproteinemia): the role of apolipoprotein $\mathrm{E}$ in normal and abnormal lipoprotein metabolism. In The Metabolic Basis of Inherited Disease. C. R. Scriver, A. L. Beaudet, W. S. Sly, and D. Valle, editors. McGraw-Hill, New York. 1195-1213.

13. Deckelbaum, R. J., E. Granot, Y. Oschry, L. Rose, and S. Eisenberg. 1984. Plasma triglyceride determines structure-composition in low and high density lipoproteins. Arteriosclerosis. 4:225-231.

14. Albers, J. A., J. H. Tollefson, C.-H. Chen, and A. Steimetz. 1984. Isolation and characterization of human lipid transfer proteins. Arteriosclerosis. 4:49-58.

15. Mims, M. P., J. R. Guyton, and J. D. Morrisett. 1986. Microemulsions of cholesterol oleate and dimyristoylphosphatidylcholine: a model for cholesterol ester rich very low density lipoproteins. Biochemistry. 25:474-483.

16. Deckelbaum, R. J., G. G. Shipley, and D. M. Small. 1977. Structure and interactions of lipids in human plasma low density lipoproteins. J. Biol. Chem. 252:744-754.

17. Pownall, H. J., J. Shepherd, W. W. Mantulin, L. A. Sklar, and A. M. Gotto. 1980. Effect of saturated and polyunsaturated fat diets in the composition and structure of human low density lipoproteins. Atherosclerosis. 36:299-314.

18. Pownall, H. J., R. L. Jackson, R. L. Roth, A. M. Gotto, J. R. Patsch, and F. A. Kummerow. 1980. Influence of an atherogenic diet on the structure of swine low density lipoproteins. J. Lipid Res. 21:1108-1115.

19. National Institute of Health Consensus Development Conference on the Treatment of Hypertriglyceridemia. 1984. Treatment of hypertriglyceridemia JAMA (J. Am. Med. Assoc.). 251:1196-1200.

20. Patsch, J. R., S. Sailer, G. Kostner, F. Sandhofer, A. Holasek, and H. Braunsteiner. 1974. Separation of the main lipoprotein density classes from human plasma by rate zonal ultracentrifugation. J. Lipid Res. 15:356-366.

21. Nichols, A. V., R. M. Krauss, and T. A. Musliner. 1986. Nondenaturing polyacrylamide gradient gel electrophoresis. Methods Enzymol. 128:417-430.

22. Laemmli, U. K. 1970. Cleavage of structural proteins during the assembly of the head of bacteriophage T4. Nature (Lond.). 227:680-685.

23. Kirchausen, T., S. H. Untracht, G. H. Fless, and A. M. Scanu. 1979. Atherogenic diets and neutral lipid organization in plasma low density lipoproteins. Atherosclerosis. 33:59-70.

24. Markwell, M. A. K., S. M. Haas, L. L. Bieber, and N. E. Tolbert. 1978. A modification of the Lowry procedure to simplify protein determination in membrane and lipoprotein samples. Anal. Biochem. 87:206-210.

25. Basu, S. K., J. L. Goldstein, R. G. W. Anderson, and M. S. Brown. 1976. Degradation of cationized low density lipoprotein and regulation of cholesterol metabolism in homozygous familial hypercholesterolemia fibroblasts. Proc. Natl. Acad. Sci. USA. 73:3178-3182.

26. Johnson, W. C., Jr. 1990. Protein secondary structure and circular dichroism: a practical guide. Proteins. 7:205-214.

27. Goldstein, J. L., S. K. Basu, and M. S. Brown. 1983. Receptor mediated endocytosis of low density lipoproteins in cultured cells. Methods Enzymol. 98:241-260.

28. Kunitake, S. T., S. G. Young, G. C. Chen, C. R. Pullinger, S. Zhu, R. P. Pease, J. Scott, P. Hass, J. Schilling, and J. P. Kane. 1990. Conformation of apolipoprotein B-100 in the low density lipoproteins of tangier disease. J. Biol. Chem. 265:20739-20746.

29. Wang, S. R., M. Pessah, J. Infante, D. Catala, C. Salvat, and R. Infante. 1988. Lipid and lipoprotein metabolism in Hep G2 cells. Biochim. Biophys. Acta. 961:351-363.

30. Dashti, N., G. Wolfbauer, E. Koren, B. Knowles, and P. Alaupovic. 1984 Catabolism of human low density lipoproteins by human hepatoma cell line HepG2. Biochim. Biophys. Acta. 794:373-384.

31. Erickson, S. K., and P. E. Fielding. 1986. Parameters of cholesterol metabolism in the human hepatoma cell line Hep-G2. J. Lipid Res. 27:875-883.

32. Schumaker, V. N., M. T. Robinson, L. K. Curtiss, R. Butler, and R. S. Sparkes. 1984. Anti-apoprotein B monoclonal antibodies detect human low density lipoprotein polymorphism. J. Biol. Chem. 259:6423-6430.

33. Austin, M. 1991. Plasma triglyceride and coronary heart disease. Arteriosclerosis. 11:2-14.

34. Barter, P. J., O. V. Rajaram, and G. D. Calvert. 1982. Triglyceride exchanges and transfers: their role in the kinetics of plasma triglyceride transport. In Lipoprotein Kinetics and Modeling. M. Berman, S. M. Grundy, and B. V. Howard, editors. Academic Press, New York. 245-251.

35. Kesaniemi, Y. A., G. L. Vega, and S. M. Grundy. 1982. Kinetics of apolipoprotein B in normal and hyperlipidemic man: review of current data. In Lipoprotein Kinetics and Modeling. M. Berman, S. M. Grundy, and B. V. Howard, editors. Academic Press, New York. 181-203.

36. Sigurdson G. 1982. Deconvolution analysis of the conversion of VLDL apoprotein B to LDL apoprotein B. In Lipoprotein Kinetics and Modeling. M. Berman, S. M. Grundy, and B. V. Howard, editors. Academic Press, New York. 113-120.

37. Vega, G. L., and S. M. Grundy. 1989. Studies on mechanisms for en- hanced clearance of low density lipoproteins in patients with primary hypertriglyceridaemia. J. Intern. Med. 226:5-15.

38. Kinoshita, M., E. S. Krul, and G. Schonfeld. 1990. Modification of the core lipids of low density lipoproteins produces selective alterations in the expression of apoB-100 epitopes. J. Lipid Res. 31:701-708.

39. Patsch, W., J. R. Patsch, G. M. Kostner, S. Sailer, and H. Braunsteiner. 1978. Isolation of subfractions of human very low density lipoproteins by zonal ultracentrifugation. J. Biol. Chem. 253:4911-4915.

40. Gambert, P., C. Bouzerand-Gambert, A. Athias, M. Farnier, and C. Lallemant. 1990. Human low density lipoprotein subfractions separated by gradient gel electrophoresis: composition, distribution, and alterations induced by cholesterol ester transfer protein. J. Lipid Res. 31:1199-1210.

41. Small, D. M. 1970. The physical state of lipids of biological importancecholesterol esters, cholesterol, and triglyceride. In Surface Chemistry of Biological Systems. E. Blank, editor. Plenum Press, New York. 55-84.

42. Adelman, S. J., J. M. Glick, M. C. Phillips, and G. H. Rothblat, 1984. Lipid composition and physical state effects on cellular cholesterol ester clearance. J. Biol. Chem. 259:13844-13850.

43. Glick, J. M., S. J. Adelman, M. C. Phillips, and G. H. Rothblat. 1983 Cellular cholesterol clearance: relationship to the physical state of cholestero ester inclusions. J. Biol. Chem. 258:13425-13430.

44. Kleinman, Y., S. Eisenberg, Y. Oschry, D. Gavish, O. Stein, and Y. Stein 1985. Defective metabolism of hypertriglyceridemic low density lipoprotein in cultured human skin fibroblasts. J. Clin. Invest. 75:1796-1803.

45. Havinga, J. R., P. Lohse, and U. Beisiegel. 1987. Immunoblotting and ligand blotting of the low density lipoprotein receptor of human liver, HepG2 cells and HeLa cells. FEBS (Fed. Eur. Biochem. Soc.) Lett. 216:275-280.

46. Semenkovich, C. F., and R. E. Ostlund. 1987. Estrogens induce low density lipoprotein receptor activity and decrease intracellular cholesterol in human hepatoma cell line Hep G2. Biochemistry. 26:4987-4992.

47. Tam, S.-P., L. Brisette, R. Ramharack, and R. G. Deeley. 1991. Differences between the regulation of 3-hydroxy-3-methylglutaryl-coenzyme A reductase and low density lipoprotein receptor in human hepatoma cells and fibroblasts reside primarily at the translational and post-translational levels. J. Biol. Chem. 266:16764-16773.

48. Stephan, Z. F., S. Lindsey, and K. C. Hayes. 1987. Taurine enhances low density lipoprotein binding: internalization and degradation by cultured Hep G2 cells. J. Biol. Chem. 262:6069-6073.

49. Havekes, L. M., D. Schouten, E. C. M. de Wit, L. H. Cohen, M. Griffioen, V. W. M. van Hinsbergh, and H. M. G. Princen. 1986. Stimulation of the LDL receptor activity in the human hepatoma cell line Hep $\mathrm{G} 2$ by high density serum fractions. Biochim. Biophys. Acta. 875:236-246.

50. Ellsworth, J. L., C. Brown, and A. D. Cooper. 1988. Stimulation of LDL receptor activity in Hep-G2 cells by a serum factor(s). J. Cell. Physiol. 135:213223

51. Havel, R. J., and R. L. Hamilton. 1988. Hepatocytic lipoprotein receptors and intracellular lipoprotein catabolism. Hepatology. 8:1689-1704.

52. Chappell, D. A., G. L. Fry, M. A. Waknitz, and J. J. Berns. 1991. Ligand size as a determinant for catabolism by the low density lipoprotein (LDL) receptor pathway. J. Biol. Chem. 266:19296-19302.

53. Pathak, R. K., M. Yokode, R. E. Hammer, S. E. Hofman, M. S. Brown, J. L. Goldstein, and R. G. W. Anderson. 1990. Tissue specific sorting of the human $\mathrm{LDL}$ receptor in polarized epithelia of transgenic mice. J. Cell Biol. 111:347-359.

54. Yokode, M., R. K. Pathak, R. E. Hammer, M. S. Brown, J. L. Goldstein, and R. G. W. Anderson. 1992. Cytoplasmic sequence required for basolatera targeting of LDL receptor in livers of transgenic mice. J. Cell Biol. 117:39-46.

55. Tolleshaug, H., K. K. Hobgood, M. S. Brown, and J. L. Goldstein. 1983 The LDL receptor locus in familial hypercholesterolemia: multiple mutations disrupt transport and processing of a membrane receptor. Cell. 32:941-951.

56. Innerarity, T. L., K. H. Weisgraber, R. W. Mahley, R. M. Krauss, G. L. Vega, and S. M. Grundy. 1987. Familial defective apolipoprotein B-100: low density lipoproteins with abnormal receptor binding. Proc. Natl. Acad. Sci. USA. 84:6919-6923.

57. Lund-Katz, S., T. L. Innerarity, K. S. Arnold, L. K. Curtiss, and M. C. Phillips. 1991. 13-C NMR evidence that substitution of glutamine for arginine 3500 in familial defective apolipoprotein B-100 disrupts the conformation of the receptor-binding domain. J. Biol. Chem. 266:2701-2704.

58. Young, S. G., J. L. Witztum, D. C. Casal, L. K. Curtiss, and S. Bernstein. 1986. Conservation of the low density lipoprotein receptor-binding domain of apoprotein B. Arteriosclerosis. 6:178-188.

59. Weintraub, M. S., S. Eisenberg, and J. L. Breslow. 1987. Different patterns of postprandial lipoprotein metabolism in normal, type IIa, type III, and type IV hyperlipoproteinemic individuals. J. Clin. Invest. 79:1110-1119.

60. Yang, C., S. Chen, S. H. Gianturco, W. A. Bradley, J. T. Sparrow, M. Tanimura, W. Li, D. A. Sparrow, H. DeLoof, M. Rosseneau, et al. 1986. Sequence, structure, receptor-binding domains and internal repeats of apolipoprotein B. Nature (Lond.). 323:738-742.

61. Yang, C., E. Gu, S. Weng, T. W. Kim, S. Chen, H. J. Pownall, P. M. Sharp S. Liu, W. Li, A. M. Gotto, et al. 1989. Structure of apolipoprotein B-100 of human low density lipoproteins. Arteriosclerosis. 9:96-108. 